\title{
The Association Between Hay Fever and Stroke in a Cohort of Middle Aged and Elderly Adults
}

\author{
Eric M. Matheson, MD, Marty S. Player, MD, MS, Arch G. Mainous, III, PhD, \\ Dana E. King, MD, MS, and Charles J. Everett, PhD
}

Background: Asthma has been linked to stroke, but it is unknown if hay fever is related to stroke. This study was designed to investigate if there is an association between a reported history of hay fever and stroke during a 4.4-year study period.

Methods: Analysis was performed of the Atherosclerosis Risk in Communities study, a cohort of middle aged and elderly adults. We examined the association of a reported history of hay fever to the development of stroke.

Results: There were 9272 participants meeting our criteria, of which 125 had strokes. Of those with a history of hay fever, $2.2 \%$ had a stroke. Of those without a history of hay fever, $1.25 \%$ had a stroke. Participants with a history of hay fever had an unadjusted hazard ratio of 1.72 (95\% CI, 1.08-2.27) for stroke versus participants without hay fever. Risk of stroke remained significant (hazard ratio, 1.87 [95\% CI, 1.17-2.99]) after controlling for age, sex, race, smoking status, body mass index, diabetes, hypertension, alcohol use, and hyperlipidemia.

Conclusion: A history of hay fever seems to be a risk factor for stroke, and this association may be an area for future research and intervention. (J Am Board Fam Med 2008;21:179-183.)

Stroke is the third leading cause of death in the United States. ${ }^{1}$ Established risk factors include smoking, hypertension, diabetes, and obesity; however, the occurrence of stroke is not fully explained by these factors alone. ${ }^{2}$

Recent research into the pathophysiology of stroke has demonstrated a possible role for increased systemic inflammation that may lead to cerebrovascular thrombotic events and stroke. ${ }^{3-5}$ Chronic inflammation from respiratory conditions may follow a similar association with stroke. One study ${ }^{6}$ found that middle age and elderly patients who reported a history of asthma had an increased risk of stroke over 14 years. Asthma and chronic hay fever share some similar pathophysiology with chronic inflammation. Thus, the presence of hay

\footnotetext{
This article was externally peer reviewed.

Submitted 12 December 2007; revised 15 February 2008; accepted 18 February 2008.

From the Department of Family Medicine at the Medical University of South Carolina, Charleston.

Funding: Supported by grant 5 D55HP05150 from the Health Resources and Services Administration.

Conflict of interest: none declared.

Corresponding author: Eric M. Matheson, MD, Department of Family Medicine, Medical University of South Carolina, PO Box 250192, 295 Calhoun Street, Charleston, SC 29425 (E-mail: matheson@musc.edu).
}

fever may contribute to an increased risk of stroke in a similar fashion as asthma through a combination of elevated blood pressure and inflammation. Considering there are an estimated 20 million adults affected by hay fever in the United States, this study was initiated to examine the association between hay fever and stroke. ${ }^{7}$

\section{Methods \\ Study Population}

We undertook an analysis of the Atherosclerosis Risk in Communities Study (ARIC) public use data set, a prospective cohort performed in Washington County, Maryland; Forsyth County, North Carolina; Jackson, Mississippi; and the suburbs of Minneapolis, Minnesota. ${ }^{8}$ The original cohort consisted of 15,792 participants who were enrolled in the ARIC study between 1987 and 1989. At the time of their first visit, the participants were between the ages of 45 and 64 . Monitoring has consisted of periodic history and physical examination, annual telephone calls, and hospital discharge and death certificate surveillance.

For the purposes of this study, we performed an analysis using information from the participants' fourth visit (1996 to 1998; visit 4) as our baseline 
because this is the only visit in which participants were questioned about a history of hay fever. Participants were followed through 31 December 2001. We excluded patients with a history of stroke or coronary heart disease because of their high risk of stroke. ${ }^{2}$ Because asthma and hay fever seem to have a similar pathophysiology, we initially performed an analysis that excluded asthma participants. We then performed an analysis that included participants with asthma to determine whether asthma may be an effect modifier or a confounding variable.

\section{Definition of Hay Fever}

For purposes of our study, hay fever was defined as a report by a participant of ever having been told by a physician that he or she had hay fever. We relied on participants' self-reporting of hay fever because formal allergy skin testing was not available in the ARIC dataset. We used the term bay fever rather than allergic rhinitis because it was the term used by the ARIC interviewers. Because of the seasonal nature of hay fever, we included participants who ever reported hay fever rather than only participants who were suffering with hay fever at the time of visit 4.

\section{Determination of Stroke Events}

The methods used in the ARIC study for evaluating stroke have been extensively outlined by Rosamond et al. ${ }^{9}$ Three methods were used to determine the incidence of stroke. First, yearly interviews were conducted with participants by telephone. Second, the records of local hospitals were reviewed for admissions of study participants during the previous year. Third, death certificates were reviewed from the vital statistics offices in the states involved in the study. In the analysis of hospital records, strokes were identified based on ICD-9 discharge codes 430 through 438 , which encompass the different stroke subtypes. In addition, strokes were identified if there was a mention of stroke in a radiologic report. This information was abstracted by a trained nurse who reviewed the hospital discharge records. Stroke cases were initially classified by a computer algorithm and then were confirmed by an expert reviewer based on criteria taken from the National Survey of Stroke. ${ }^{10}$ Discrepancies between the computer and the expert reviewer were settled by another expert reviewer. Strokes were then further stratified as "possible," "definite," or "probable" based on radiologic imaging and autopsy, if available. ${ }^{11} \mathrm{We}$ included stroke events classified as either definite or probable. Strokes were also defined as ischemic or hemorrhagic but, because of the small number of hemorrhagic strokes (17 out of 125), we used both ischemic and hemorrhagic strokes for our stroke events without differentiating between the 2 types. We also performed an analysis of ischemic strokes alone.

\section{Control Variables}

Several variables have been identified as risk factors for stroke and thus may be potential confounders of any relationship between hay fever and stroke. These include sex, race, smoking, body mass index, diabetes, hypertension, alcohol consumption, asthma, and hyperlipidemia. . $^{2,12-17}$

\section{Analysis}

We used the statistical package SAS (Statistical Analysis System, Cary, NC) for all analyses. We used $\chi^{2}$ tests to examine, for each of the control variables, the bivariate relationships between participants with and without a history of hay fever. We computed an unadjusted Cox regression to determine the relationship between hay fever and risk of future stroke. Two multivariate Cox regressions were performed: one with adjustment for age and smoking because those 2 variables were significant in bivariate analysis; and one including all pre-specified control variables. In addition to our primary analysis we conducted a further analysis to determine whether participants with a history of hay fever and antihistamine usage, a possible proxy for severity of hay fever, were at greater risk of stroke than participants with a history of hay fever who did not use antihistamines. We determined if the participants used antihistamines based on the medical history obtained during visit 4 .

\section{Results}

Our cohort consisted of 9272 eligible participants at baseline, with a mean follow-up of 4.4 years and an average age of 62.4 years. There were 125 definite or probable strokes during follow-up, and $10.4 \%$ of the cohort had a previous diagnosis of hay fever. In bivariate relationships, age and smoking were significantly different between the hay fever and non-hay fever groups (Tables 1 and 2). Younger participants and those who did not smoke had more hay fever. 
Table 1. Demographics of Participants Free of Cardiovascular Disease at Visit 4 of the Atherosclerosis Risk in Communities Study

\begin{tabular}{|c|c|}
\hline Characteristic & $\begin{array}{c}\text { Participants } \\
(\mathrm{n}=9272)(\%)\end{array}$ \\
\hline \multicolumn{2}{|l|}{ Ever told had hay fever } \\
\hline No & 89.6 \\
\hline Yes & 10.4 \\
\hline \multicolumn{2}{|l|}{ Sex } \\
\hline Male & 41.6 \\
\hline Female & 58.4 \\
\hline \multicolumn{2}{|l|}{ Race } \\
\hline Non African-American & 77.6 \\
\hline African-American & 22.4 \\
\hline \multicolumn{2}{|l|}{ Smoking status } \\
\hline Non-smoker & 85.0 \\
\hline Current smoker & 15.0 \\
\hline Mean body mass index $\left(\mathrm{kg} / \mathrm{m}^{2}\right)$ & $28.7(5.6)^{*}$ \\
\hline \multicolumn{2}{|l|}{ Diabetes } \\
\hline No & 84.8 \\
\hline Yes & 15.2 \\
\hline \multicolumn{2}{|l|}{ Hypertension } \\
\hline No & 54.9 \\
\hline Yes & 45.1 \\
\hline \multicolumn{2}{|l|}{ Alcohol } \\
\hline$<350 \mathrm{~g} / \mathrm{wk}$ & 98.9 \\
\hline$\geq 350 \mathrm{~g} / \mathrm{wk}$ & 1.1 \\
\hline \multicolumn{2}{|l|}{ Total cholesterol } \\
\hline$\leq 240 \mathrm{mg} / \mathrm{dL}$ & 86.2 \\
\hline$>240 \mathrm{mg} / \mathrm{dL}$ & 13.8 \\
\hline
\end{tabular}

*Value given as standard deviation.

Of those with hay fever, $2.2 \%$ had stroke compared with $1.25 \%$ of those without hay fever $(P=$ $.02)$. The adjusted hazard ratios (HRs) show that a history of hay fever is a significant risk factor for the development of stroke even after controlling for relevant confounding variables (Table 3 ). We performed an adjusted Cox's regression of combined ischemic and hemorrhagic strokes excluding asthmatics, which demonstrated that participants with hay fever had a much greater risk of stroke than those without hay fever (HR, 1.87; 95\% CI, 1.172.99). We then performed an adjusted Cox's regression of study participants for combined ischemic and hemorrhagic strokes including asthmatics and found that participants with hay fever had a significantly greater risk of stroke than those without hay fever (HR, 1.83; 95\% CI, 1.18-2.84), even when we controlled for the aforementioned covariates as well as asthma. We then performed an
Table 2. Bivariate Relationship of Hay Fever Distribution for Each Control Variable

\begin{tabular}{|c|c|c|}
\hline & Hay Fever (\%) & $\chi^{2} P$ \\
\hline Age (yr) & & .04 \\
\hline $52-57$ & 11.71 & \\
\hline $58-61$ & 10.77 & \\
\hline $62-66$ & 9.78 & \\
\hline $67-70$ & 9.28 & \\
\hline Sex & & .20 \\
\hline Male & 9.92 & \\
\hline Female & 10.74 & \\
\hline Race & & .21 \\
\hline Non African-American & 10.18 & \\
\hline African-American & 11.13 & \\
\hline Smoking status & & $<.01$ \\
\hline Non-smoker & 10.80 & \\
\hline Current smoker & 8.11 & \\
\hline Body mass index $\left(\mathrm{kg} / \mathrm{m}^{2}\right)$ & & .87 \\
\hline$<25$ & 10.11 & \\
\hline $25-29$ & 10.51 & \\
\hline$\geq 30$ & 10.49 & \\
\hline Diabetes & & .62 \\
\hline No & 10.46 & \\
\hline Yes & 10.03 & \\
\hline Hypertension & & .25 \\
\hline No & 10.06 & \\
\hline Yes & 10.80 & \\
\hline Alcohol & & .92 \\
\hline$<350 \mathrm{~g} / \mathrm{wk}$ & 10.39 & \\
\hline$\geq 350 \mathrm{~g} / \mathrm{wk}$ & 10.68 & \\
\hline Total cholesterol & & .93 \\
\hline$\leq 240 \mathrm{mg} / \mathrm{dL}$ & 10.41 & \\
\hline$>240 \mathrm{mg} / \mathrm{dL}$ & 10.33 & \\
\hline
\end{tabular}

adjusted Cox's regression for only ischemic strokes that excluded asthmatics and that showed participants with hay fever had a significantly greater risk of ischemic stroke than those without hay fever (HR, 1.72; 95\% CI, 1.03-2.90). Finally, we examined antihistamine use as a possible proxy for the severity of hay fever. In an adjusted Cox's regression, with no hay fever and no antihistamine use as the reference category, the risks progressed from no hay fever and some antihistamine use (HR, 1.02; 95\% CI, 0.41-2.51) to hay fever and no antihistamine use (HR, 1.76; 95\% CI, 1.05-2.95) to hay fever and some antihistamine use (HR, 2.50; 95\% CI, 0.92-6.83).

\section{Discussion}

The primary finding of this study is that patients with a history of hay fever have a higher risk of 
Table 3. Cox's Regressions for Risk of Developing Stroke in Middle-Aged Participants with a History of Hay Fever

Hazard Ratio (95\% CI)

\begin{tabular}{ll} 
History of hay fever* & \\
No & $1.00(\mathrm{NA})$ \\
Yes & $1.72(1.08-2.27)$ \\
History of hay fever ${ }^{\dagger}$ & $1.00(\mathrm{NA})$ \\
$\quad$ No & $1.91(1.19-3.05)$ \\
Yes & \\
History of hay fever & \\
No & $1.00(\mathrm{NA})$ \\
Yes & $1.87(1.17-2.99)$ \\
\hline
\end{tabular}

*Unadjusted Cox regression analysis.

${ }^{\dagger}$ Adjusted for age (continuous), and smoking status.

${ }^{\ddagger}$ Adjusted for age (continuous), sex, race, smoking status, body mass index (continuous), diabetes, hypertension, alcohol $\geq 350$ $\mathrm{g} /$ week, and total cholesterol $>240 \mathrm{mg} / \mathrm{dL}$.

NA, not applicable.

suffering a stroke over 4.4 years of follow-up. These results were maintained after controlling for factors that might confound the relationship, including age, sex, race, smoking status, body mass index, diabetes, alcohol use, asthma, and hyperlipidemia.

The results of this study indicate that hay fever is an independent risk factor for first stroke. Furthermore, patients with hay fever who use antihistamines may be at particularly great risk. Whether this is caused by more severe hay fever or some iatrogenic response to antihistamines is unclear. Hay fever, which has previously been viewed as a benign condition, may be a contributor to cerebrovascular risk. Because over $8.6 \%$ of the United States population suffers from hay fever, this study's findings may have broad public health implications regarding who may be at risk of stroke and may increase the need for risk factor modification in people suffering from chronic allergy symptoms. ${ }^{18}$

One mechanism by which the risk of stroke may be increased is through hypertension induced by hay fever. ${ }^{19,20}$ Our analysis, however, suggests that the association between hay fever and stroke remained even after controlling for diagnosed hypertension.

Hay fever is a disease associated with systemic inflammation. During a typical allergy attack, inflammatory mediators such as histamine, leukotrienes, prostaglandins, and cytokines are released. As such, it may be this systemic inflammation that increases the risk of stroke. The findings of this study are in line with other studies involving participants with respiratory conditions and potential inflammation. For example, Low et $\mathrm{al}^{21}$ showed that upper respiratory infections, grass pollen, and air pollutants led to increased hospital admissions for stroke.

This study has a few limitations of note. For the determination of hay fever, patients were identified by self-report rather than formal allergy skin testing. Specifically, the participants were asked if a physician had ever diagnosed them with hay fever. We can estimate, however, that $80 \%$ of patients who are identified as having allergies by a physician will have a positive allergy skin test. ${ }^{22,23}$ Furthermore, the number of affected participants in our dataset is consistent with the 2002 Chartbook on Trends in the Health of Americans, ${ }^{18}$ which found that in patients ages 45 to 64 the prevalence of hay fever was $10.8 \%$.

In conclusion, a history of hay fever seems to be a risk factor for stroke, and this association may be an area for future research and intervention.

\section{References}

1. Rosamond W, Flegal K, Friday G, et al. Heart disease and stroke statistics-2007 update: a report from the American Heart Association Statistics Committee and Stroke Statistics Subcommittee. Circulation 2007;115:e69-171.

2. Straus S, Majumdar S, McAlister F. New evidence for stroke prevention. JAMA 2002;288:1388-95.

3. Paeletti R, Gotto AM Jr, Hajjar DP. Inflammation in atherosclerosis and implications for therapy. Circulation 2004;109(23 Suppl 1):III20-6.

4. Rost NS, Wolf PA, Kase CS, et al. Plasma concentration of C-reactive protein and risk of ischemic stroke and transient ischemic attack: the Framingham Study. Stroke 2001;32:2575-9.

5. Cao JJ, Thach C, Manolio TA, et al. C-reactive protein, carotid intima-media thickness, and incidence of ischemic stroke in the elderly: the Cardiovascular Health Study. Circulation 2003;108:16670.

6. Schanen JG, Iribarren C, Shahar E, et al. Asthma and the incident of cardiovascular disease: the Atherosclerosis Risk in Communities Study. Thorax 2005;60:633-8.

7. US Census Bureau. Census Bureau estimates the number of adults, older people and school age children in states [press release]. Washington DC: US Census Bureau; 2004.

8. The Atherosclerosis Risk in Communities (ARIC) 
Study: design and objectives. The ARIC investigators. Am J Epidemiol 1989;129:687-702.

9. Rosamond WD, Folsom AR, Chanbless LE, et al. Stroke incidence and survival among middle-age adults: 9-year follow-up of the Atherosclerosis Risk in Communities (ARIC) cohort. Stroke 1999;4: 351-9.

10. The National Survey of Stroke. National Institute of Neurological and Communicative Disorders and Stroke. Stroke 1981;12(2 Pt 2 Suppl 1):I1-91.

11. Ohira T, Shahar E, Chambless LE, Rosamond WB, Mosley TH Jr, Folson AR. Risk factors for ischemic stroke subtypes: the Atherosclerosis Risk in Communities Study. Stroke 2006;37:2493-8.

12. Hollander M, Koudstaal PJ, Bots ML, Grobbee DE, Hofman A, Breteler MM. Incidence, risk, and case fatality of first ever stroke in the elderly population. The Rotterdam Study. J Neurol Neurosurg Psychiatry 2003;74:317-21.

13. Seshadri S, Beiser A, Kelly-Hayes M, et al. The lifetime risk of stroke: estimates from the Framingham Study. Stroke 1992;23:1551-5.

14. From the Centers for Disease Control and Prevention. Age-specific excess deaths associated with stroke among racial/ethnic minority populationsUnited States, 1997. JAMA 2000;283:2382-3.

15. Ueshima H, Choudhury SR, Okayama A, et al. Cigarette smoking as a risk factor for stroke death in Japan. Stroke 2004;35:1836.

16. Almdal T, Scharling H, Jensen JS, et al. The independent effect of type 2 diabetes mellitus on isch- emic heart disease, stroke, and death: a populationbased study of 13,000 men and women with 20 years of follow-up. Arch Inter Med 2004;164:1422-6.

17. Hansagi H, Romelsjo A, Verdier M, et al. Alcohol consumption and stroke mortality: 20 year follow-up of 15,077 men and women. Stroke 1995;26:1768-73.

18. National Center for Health Statistics. Health, United States, 2005: Chartbook on Trends in the Health of Americans. Hyattsville (MD): National Center for Health Statistics; 2005.

19. Magen E, Yosefy C, Viskoper RJ, et al. Treatment of allergic rhinitis can improve blood pressure control. J Hum Hypertens 2006;20:888-93.

20. Kony S, Zureik M, Neukirch C, Leynaert B, Vervloet D, Neukirch F. Rhinitis is associated with increased systolic blood pressure in men: a population based study. Am J Respir Crit Care Med 2003;167: 538-43.

21. Low RB, Bielory L, Qureshi AI, Dunn V, Stuhlmiller DFE, Dickey DA. The relation of stroke admission to recent weather, airborne allergens, air pollution, seasons, upper respiratory infections, and asthma incidence, September 11, 2001, and day of the week. Stroke 2006;37:951-7.

22. Calabria CW, Dice J. Aeroallergen sensitization rates in military children with rhinitis symptoms. Ann Allergy Asthma Immunol 2007;99:161-9.

23. Lane AP, Pine HS, Pillsbury HC 3rd. Allergy testing and immunotherapy in an academic otolaryngology practice: a 20-year review. Otolaryngol Head Neck Surg 2001;124:9-15. 